\title{
ASPECTOS SOCIAIS E TECNOLÓGICOS DAS ATIVIDADES DE INOVAÇÃO
}

Thales Novaes de Andrade

A inovação é um conceito que vem adquirindo grande espaço nas Ciências Sociais. A partir dos anos 90, diversos autores passaram a discutir as articulações das novas tecnologias informáticas e biológicas com os processos reprodutivos, o financiamento estatal e as condições ambientais, para dar alguns exemplos (Maciel, 1996; Martins, 2003; Castells, 2003; Trigueiro, 2002; Latour, 2000).

Nos países avançados, essa problemática adentrou na agenda de diferentes setores como governos, corporações, universidades, centros de pesquisa e movimentos sociais. Desde os anos 80, os países da Organização para a Cooperação e Desenvolvimento Econômico (OCDE) vêm alterando o padrão de apoio à indústria, incorporando medidas de inovação que integram a política de comércio internacional com a industrial e tecnológica. Ao invés de subvencionarem empresas através de contratos de Pesquisa \& Desenvolvimento específicos e pontuais, os governos desses países passaram a criar condições para que a atividade produtiva se organize de forma sistêmica e integrativa (Cassiolato \& Lastres, 2000).

Em comparação com a Economia e as Ciências Organizacionais, as Ciências Sociais estão menos presentes nessa 
agenda de pesquisa. O tema da inovação mantém-se mais ligado a preocupações de ordem econômica, como competitividade, pressões da demanda, investimento e análises prospectivas. Persistem os estudos de caso e análises de setores de atividades que focam especificamente a atuação de empresas, agências incubadoras, órgãos públicos de fomento e instituições de pesquisa (Barbieri, 2005; Mowery \& Rosenberg, 2005).

Alguns autores têm chamado atenção para o desafio preemente de se incluir variáveis socioculturais nas avaliações e estudos sobre a implementação da inovação em contextos locais e nacionais (Maciel, 2002; Albagli \& Maciel, 2004). A presença de atores da sociedade civil na prática inovativa representa atualmente um dos grandes temas a serem investigados. Mais do que espectadores ou consumidores de inovações ou equipamentos novos, os diversos atores da sociedade civil constituem elementos-chave para a

140 viabilidade ou não de determinados projetos tecnológicos, e faz-se necessário administrar melhor a atividade inovativa para criar ambientes de circulação de informação mais abertos e eficientes.

Atualmente a questão da gestão da prática tecnológica e os arranjos institucionais para facilitar os fluxos de conhecimento têm ocupado o centro das atenções dos cientistas sociais ligados ao tema da inovação (Gibbons et al., 1994).

Além dessa questão da incorporação da sociedade civil nas atividades de inovação e a gestão do conhecimento social, outro tema tem mobilizado alguns cientistas sociais e filósofos das técnicas, que consiste na questão da especificidade da discussão técnica. Até que ponto a problemática da inovação em termos econômicos e sociológicos poderia prescindir de uma atenção à prática tecnológica? A Sociologia da Inovação pode focar mais detidamente as instituições de pesquisa e a gestão dos fluxos de conhecimento sem se ater à dinâmica própria dos objetos técnicos? Em outras 
palavras, é viável discutir a inovação social separada da inovação tecnológica?

O presente artigo pretende debater essas tendências, partindo do princípio de que os estudos econômicos, sociológicos e filosóficos acerca da inovação tecnológica precisam adquirir mais coerência de modo a solucionar os impasses teóricos presentes na discussão atual. Ele procurará tratar exatamente desses impasses que envolvem a incorporação dos diferentes atores sociais na construção da inovação tecnológica. Em um primeiro momento, será tratada a relação entre fatores econômicos e sociais no processo de inovação. Posteriormente serão discutidas questões envolvendo inovação e gestão do conhecimento, um assunto que atualmente concentra grande parte dos pesquisadores atentos à dinâmica entre comportamento coletivo e desenvolvimento; e por fim retomar a discussão sobre a importância da tecnicidade e da configuração dos objetos técnicos para se entender o processo inovativo.

Espera-se ao final dessa trajetória lançar questões sobre a problemática da imponderabilidade do processo inovativo, e conseqüentemente a articulação entre aspectos técnicos e sociais na construção da inovação.

\section{Inovação: entre o econômico e o social}

A disciplina econômica foi a que sem dúvida deu o maior impulso à construção da agenda da inovação. As elaborações de Joseph Schumpeter, no início do século XX, tiveram um impacto considerável no debate sobre transformações tecnológicas e desenvolvimento econômico. Segundo ele, as novas combinações de produtos e processos produtivos de uma empresa repercutem diretamente em seu desempenho financeiro. O comportamento empreendedor, com a introdução e ampliação de inovações tecnológicas e organizacionais nas empresas, constituiu um fator essencial para as transformações na esfera econômica e seu desenvolvimento no longo prazo (Schumpeter, 1982). 
De grande destaque nas últimas décadas, a perspectiva schumpeteriana de análise levou à formulação de diversos modelos de inovação e projeções macroeconômicas. O cruzamento de informações sobre patenteamento de produtos e investimentos públicos e privados na área tecnológica permitiu a elaboração de fórmulas e modelos para se avaliar os efeitos do mercado sobre as práticas de inovação, a célebre problemática da indução pela demanda (Flichy, 1995).

O termo inovação foi cunhado no âmbito da OCDE nos anos $70 \mathrm{com}$ vistas a promover uma interação mais efetiva entre o setor produtivo e as áreas de Pesquisa e Desenvolvimento (P\&D). Isso ocorreu no momento em que a abertura de mercados e o aumento da competitividade internacional incitaram empresas e governos a estabelecerem sinergias envolvendo pesquisa tecnológica e política industrial, para a manutenção das taxas de crescimento econômico. Christopher Freeman defende que o processo inovativo 142 deve propiciar as condições para que empresa e governo estabeleçam intercâmbios de recursos e informações para efetivar um bom desempenho na economia internacional frente às oscilações de mercado e ameaças da concorrência. (Ver Freeman, 1992; 1982.)

Diferentes perspectivas de análise foram construídas para se lidar com a questão da inovação. Uma das primeiras vertentes da pesquisa sobre inovação foi a teoria da hélice tripla, que se propunha a entender os processos inovadores a partir da conjugação de três segmentos: empresas, universidades e o Estado. O encontro entre pesquisadores, formuladores de políticas e empresários garantiria o desenvolvimento de empreendimentos cruzados de atividade científica e tecnológica.

O grande problema enfrentado pelas análises baseadas na perspectiva tradicional da hélice tripla é que elas atendiam geralmente a inovações pontuais e específicas. Dava-se dessa forma uma grande ênfase nos produtos gerados pela 
atividade tecnológica, os setores produtivos (clusters), e sua capacidade de entrada no mercado, independentemente dos formatos institucionais subjacentes a cada processo de inovação e os impactos sociais decorrentes (Maciel, 2001).

A partir dos anos 80, os economistas passaram a mudar o enfoque de análise. Os produtos específicos a serem desenvolvidos e os efeitos da oferta de recursos e da demanda de trabalho na indução à inovação deixam de representar o centro das atenções da prática inovativa. Com a globalização da economia e a flexibilização dos formatos organizacionais envolvendo empresas, agências estatais e centros de pesquisa, a formação e desenvolvimento de redes e os sistemas nacionais de inovação passam a ser temas centrais para os pesquisadores (Freeman, 1992; Cassiolato \& Lastres, 2000).

Outro tema saliente sobre a questão da inovação consiste na referência recorrente à problemática do desenvolvimento. A partir do viés schumpeteriano, os teóricos do crescimento reduziram a questão da inovação a gastos com $\mathrm{P} \& \mathrm{D}$ e capital humano à busca de modos de projetar e produzir bens a partir da referência dos próprios agentes produtivos, o que mantém a ênfase na pesquisa industrial e no comportamento empresarial como liderança na prática inovativa (Mowery \& Rosenberg, 2005). A perspectiva incremental dessas abordagens trata o processo de avanço tecnológico como algo dado e incontestável, para o qual governos, institutos de pesquisa e empresas devem confluir. (Nicolas \& Mytelka, 1994: 7)

A partir dos anos 80, os cientistas sociais têm debatido os problemas da visão econômica sobre o processo inovativo e uma das questões centrais repousa nas relações que se estabelecem entre desenvolvimento e inovação. Toda inovação implica necessariamente em desenvolvimento? Ou inversamente: a concepção vigente de desenvolvimento econômico e social pode servir de parâmetro para se avaliar processos inovadores? Essas são perguntas que de diferentes 
formas têm instigado os cientistas sociais e filósofos interessados na problemática da inovação tecnológica.

Um primeiro problema que se coloca na relação entre inovação e desenvolvimento é que este último se ancora em um postulado ontológico, o qual se torna essencial e normativo para as sociedades modernas. A ideologia desenvolvimentista que vigorou no ideário econômico e político do Pós-Guerra possibilitou a normatização da prática social em torno de preceitos como crescimento, avanço ou modernização. Esse ideal de desempenho econômico e social foi estabelecido como a expressão dominante dos enfoques econômicos e políticos durante várias décadas, tendo como exemplo a teoria da dependência, os trabalhos da Cepal e as teorias do crescimento.

O problema do desenvolvimento, apesar de apresentar diversos limites e contratendências, adquire um estatuto de existência que se torna inquestionável. É possível discutir as 144 variáveis do crescimento econômico e os fatores estruturais de estagnação e recessão através de modelos e escalas, mas a ocorrência própria do desenvolvimento, enquanto forma cumulativa, linear e contínua de desempenho produtivo é indiscutível dentro da tradição econômica e sociológica das últimas décadas (Nicolas \& Mytelka, 1994).

Ao se adentrar na perspectiva da inovação tecnológica, essa ontologia não existe, ou se manifesta de formas diferentes. Diferentemente da lógica da invenção, a inovação não se baseia na busca de novas propriedades técnicas ou novos produtos. Sua ênfase recai sobre a compatibilização entre o avanço tecnológico e as instituições sociais existentes, ou, nos termos de Gille, entre o sistema técnico e os outros sistemas sociais (Gille, 1978).

Segundo esse autor, assiste-se no mundo contemporâneo a uma modificação decisiva entre progresso científico, invenção e inovação. O advento da Revolução Industrial estabeleceu a relação de continuidade envolvendo: progresso cientí- 
fico - invenção - inovação, de modo que o processo inovativo representa o final de uma cadeia, em que a prática tecnológica se articula com os outros sistemas sociais, provocando resistências e re-significando as diferentes instituições.

A inovação se constitui então em uma arena de relações imprevisíveis, um encontro de racionalidades diversas que adquirem uma conformação circunstancial a partir da troca de experiências entre setores produtivos, consumidores, gestores públicos, experts entre outros. Ou seja, não existem princípios evolutivos que determinem aprioristicamente os rumos do processo inovativo.

A tendência atual, contudo, de constituição de uma tecnociência altera decisivamente esse panorama. A ligação entre os componentes do avanço tecnológico se organiza da seguinte forma: invenção - inovação - crescimento. A inovação passa a ser o meio e o instrumento para efetivação do crescimento econômico. Isso implicará em uma instrumentalização da prática inovativa com vistas unicamente ao crescimento, tornando-o contido e programável.

A sociologia construtivista foi responsável por um sério questionamento da perspectiva schumpeteriana, que defende a aproximação do desenvolvimento econômico à lógica da inovação.

Os trabalhos de Pinch \& Bijker (1987), Latour (2000) e Callon (1987), apesar de suas diferenças, oferecem um olhar especial à relação entre tecnologia e economia que modificou amplamente a compreensão da dinâmica inovativa. O determinismo presente no debate econômico sobre a lógica e os modelos de inovação, relacionado à noção de difusão e racionalidade dos agentes, precisam dar lugar a uma abordagem contextual e multilinear, que não aceita se limitar aos parâmetros das escolhas econômicas.

A escolha de determinadas tecnologias e a recusa de outras não se baseia em critérios puramente econômicos ou racionais, mas sim na compatibilização envolvendo crenças 
e interesses dos diversos grupos e setores estratégicos que se encontram na atividade tecnológica. Feenberg (1999) corrobora os argumentos dos construtivistas e afirma que:

“... a escolha entre alternativas não depende essencialmente da eficiência técnica ou econômica, mas do "encaixe" entre os aparelhos e os interesses e crenças dos vários grupos sociais que influem no processo de design. O que é específico em um artefato é a sua relação com o ambiente social, e não alguma propriedade intrínseca..." (Feenberg, 1999: 79, grifo original.)

Nesse sentido, os interesses econômicos acompanham, mas não determinam o rumo da inovação. O conceito de ambientes de inovação representa um enfoque diferenciado acerca das possibilidades de construção da prática da inovação, visando articular tecnologia, economia e vida social de uma maneira diferenciada e aberta, distante do padrão que 146 relaciona a inovação tecnológica exclusivamente ao setor produtivo (Maciel, 2001).

Ele consiste de um espaço institucional e de relações de forças abertas e intangíveis que um grupo disponibiliza para implementar práticas que sejam inovadoras. Segundo a definição de Maciel o ambiente de inovação

“... procura dar conta do conjunto de condições - limites, obstáculos, possibilidades, estímulos - da inovação em uma determinada formação social. Ambiente de inovação referese, portanto, ao conjunto de fatores políticos, econômicos, sociais e culturais que estimulam ou dificultam a inovação..." (Maciel, 1997: 109)

Os ambientes de inovação levam em consideração elementos advindos da herança cultural e da criatividade peculiar de um grupo social, que tradicionalmente não são reconhecidos como componentes de inovação. 
Em seu trabalho sobre o caso italiano nos anos 80, Maciel (1996) utiliza a noção de ambiente e detecta um importante componente cultural e estético que explica o grande impulso à inovação que o país atravessou, independentemente do contexto macroeconômico regional do período. Naquele país se constituiu um ambiente de inovação especialmente propício para arranjos institucionais e diálogos entre empresas, governos e incubadoras de forma plural e criativa, o que em outros países não se deu na mesma intensidade.

Empresas, órgãos governamentais, trabalhadores, universidades, partidos e institutos de pesquisa conformaram uma grande rede, disforme e cambiante, que possibilitou a construção de um modelo específico, fruto de arranjos interdisciplinares e interinstitucionais propícios ao incremento das inovações tecnológicas. Sem essa conjugação de esforços e interesses, específicos ao caso italiano em um determinado período, o desempenho da Itália provavelmente não teria o mesmo efeito.

A entrada dos cientistas sociais no debate sobre inovação e desenvolvimento a partir dos anos 80 propiciou uma séria crítica ao incrementalismo schumpeteriano e a possibilidade de estabelecimento de uma nova agenda de pesquisa, centrada nos fluxos de conhecimento.

\section{Inovação e conhecimento}

A chegada da Economia do Conhecimento, em meados dos anos 90, teve um grande impacto nessa discussão, na medida em que adicionou a esta um aspecto pedagógico, além da já consolidada dimensão industrial e tecnológica. A interação das firmas com e no sistema passa a adquirir significado estratégico e os padrões de eficiência dependem do domínio de práticas organizacionais complexas. Essas capacidades, que anteriormente eram consideradas como que mais puramente administrativas ou gerenciais, são con- 
sideradas no período atual como parâmetros de inovação (Lemos, 2000).

A construção de novos formatos organizacionais e a ênfase em atividades de parceria, prestação de serviços, intercâmbios e convênios envolvendo empresas, governos, universidades, incubadoras e centros de pesquisa em regras múltiplas e variáveis passam a constituir a pré-condição para qualquer inovação. A crítica aos padrões lineares e simplistas de inovação, que enfocavam as relações estritas entre mercado e indústria, permitiu a construção de uma agenda de pesquisa centrada na difusão de informações e conhecimento e novas variáveis de análise (Nicolas \& Mytelka, 1994).

Portanto, ocorre uma abrangência cada vez maior do conceito de inovação, que passa a incorporar bens intangíveis em adição às variáveis econômicas presentes nas discussões anteriores. A produção e circulação de conhecimento, tácito ou codificado, passa a ser considerada um elemento essencial 148 para a efetivação das práticas de inovação tecnológica. A passagem de formas de conhecimento, em atuação pública ou privada, redefinem o sentido da inovação, de modo que

"a capacidade de gerar, de adaptar/recontextualizar e de aplicar conhecimentos, de acordo com as necessidades de cada organização, país e localidade, é, portanto, central. Desse modo, tão importante quanto a capacidade de produzir novo conhecimento é a capacidade de processar e recriar conhecimento, por meio de processos de aprendizado; e, mais ainda, a capacidade de converter esse conhecimento em ação, ou, mais especificamente, em inovação...” (Albagli \& Maciel, 2004: 10)

O contexto de comunicação entre os agentes participantes da prática inovativa torna-se assim o pressuposto para que ocorra um compartilhamento de códigos e iniciativas e, desse modo, o fluxo de idéias e práticas cooperativas. 
De acordo com essa corrente de pensamento, a inovação depende menos de investimento intensivo de capital e inventividade técnica, e mais da criação de redes de circulação de informação e conhecimento. A problemática da inovação torna-se menos tecnológica e mais pedagógica, adquire um sentido econômico (distributivo) e social (coesão) que transcende os ditames operacionais e funcionais dos objetos técnicos. Segundo Lemos,

“... com o potencial oferecido pelos novos meios técnicos disponibilizados com as tecnologias de informação, intensifica-se a geração e absorção de conhecimento e as possibilidades de implementação das inovações. As exigências de especialização ao longo da cadeia de produção se tornam cada vez maiores. As novas tecnologias acarretam, assim, tanto os meios para a cooperação, como a necessidade de criação de mais intensivas e variadas formas de interação e aprendizado intensivo." (Lemos, 2000: 170)

Os arranjos organizacionais e os formatos interativos entre agentes científicos e econômicos tomam o centro do debate inovativo. O conteúdo específico de uma determinada tecnologia não é tão relevante quanto o arcabouço gerencial e o sistema cooperativo criado em seu entorno. Ainda segundo a autora,

"Indica-se uma tendência crescente de constituição de formatos organizacionais específicos entre diferentes tipos de agentes sociais e econômicos, em ambientes propícios para a geração de inovações, envolvendo desde etapas de pesquisa e desenvolvimento e produção, até a comercialização. Tais formas de interação vêm interligando as diversas unidades de uma empresa, bem como articulam diferentes empresas e outros agentes... visando promover uma fertilização cruzada 
de idéias, responder e se adequar às rápidas alterações, com a promoção de mudanças e aperfeiçoamentos nas estruturas de pesquisa, produção e comercialização." (Lemos, 2000: 170)

A prática da gestão e compartilhamento do conhecimento e dos bens intangíveis constitui o meio e o fim da atividade dos inovadores. Faz-se necessário expandir o conceito de inovação de forma a incluir as condições coletivas para a qualificação de profissionais, aperfeiçoamento de parcerias e agilidade corporativa (Maciel, 2002; Gibbons et al., 1994).

Castells \& Hall (1994) discutem a constituição de uma geografia da inovação espalhada por diversas cidades, onde se formam meios inovadores responsáveis pela interconexão de produtos e processos dentro de uma articulação interdependente e hierarquizada. Constata-se que, na análise des150 ses meios inovadores, como o Vale do Silício, sobressaem agentes altamente tecnológicos, articulados entre empresas e centros de pesquisa de ponta dentro de formatos múltiplos e inconstantes.

As formas de utilização e percepção das tecnologias digitais implicam novas formas de coesão e relacionamento interinstitucionais. Percebe-se uma instabilidade crescente em termos de configuração de formas de utilização e aperfeiçoamento de máquinas, de modo que as hierarquias e fórmulas de propriedade e patenteamento dos produtos tecnológicos são fortemente modificadas.

As situações técnicas e sociais que se engendram entre o Estado, empresas e Universidades conformam redes de instituições que viabilizam o aprimoramento das práticas de qualificação de recursos humanos e fórmulas de patenteamento de novos conhecimentos, o que vem demandando a utilização de conceitos e abordagens das Ciências Sociais, Psicologia e Administração. 
A discussão sobre produção e circulação de conhecimento em ambientes de inovação social abre a perspectiva de análise baseada no capital social de um determinado contexto local, o que tem propiciado condições para a condução de pesquisas envolvendo técnicas sociais e circulação de saberes. O conceito de capital social formulado por Putnam et al. (1996) fornece condições para a inserção da discussão inovativa na dinâmica do compartilhamento de informações e do aprendizado interativo, dentro de um espírito cívico que envolve compromisso coletivo e divisão de riscos e oportunidades. O crescimento econômico e a redistribuição de riqueza dependem fortemente da aquisição de uma capacidade coletiva de interação e eficiência entre os diferentes agentes. A discussão trazida por Putnam et al. (1996) envolve a discussão sobre inovação, mas não se atém sobre a prática tecnológica em sua concretude. Um certo sociologismo abstrato, que leve em conta as articulações institucionais e políticas da prática tecnológica sem se importar com o gesto técnico enquanto intermediário entre homens e o meio social, tende a reduzir a inovação a práticas formais.

Todos esses aspectos apontam para um papel cada vez mais saliente de gerentes e policy makers no arranjo de práticas tecnológicas mediante novos formatos organizacionais e interações, em que a forma se sobressai aos conteúdos das atividades tecnológicas concretas.

Em suma, os inovadores muitas vezes se transformam em gerentes, ou são a eles subordinados. Essa reflexão tem conduzido várias pesquisas para um foco em inovação sem tecnologia. As instituições empresariais e de pesquisa podem ser analisadas em suas configurações internas e no seu entorno sem que se atenha especificamente a determinados objetos, como era predominante nas análises culturais de tecnologia (Ver Flichy, 1995). Esse ponto será retomado na próxima seção. 


\section{Os objetos técnicos e a inovação}

Ao lado dos investimentos econômicos e da disseminação de conhecimentos, o desenvolvimento de máquinas e conjuntos técnicos ocupa um lugar de destaque na construção da inovação. Nessa seção será discutida a importância do enfoque sobre os objetos técnicos para se entender os dilemas atuais dessa agenda de pesquisa.

Se no século XX as inovações tecnológicas se manifestaram mais claramente baseadas em objetos técnicos específicos e fixos, como o motor de combustão interna, o transistor e o computador, no período atual assiste-se a uma interligação anárquica de tecnologias e formas abertas de articulação entre produtores e consumidores. Duas tendências de desenvolvimento tecnológico podem ser detectadas: uma intimização da tecnologia, que interfere nas próprias concepções identitárias dos grupos sociais (biotecnologia); e uma tendência de conformação de grandes conjuntos téc-

152 nicos, de articulação reticular (Santos, 2000).

Dentro dessa configuração ao mesmo tempo íntima e reticular do avanço tecnológico, um aspecto essencial da sociologia contemporânea se sobressai, a contingência. Desde os anos 80 as Ciências Sociais contemporâneas estão cada vez mais abertas para o exame das relações circunstanciais e contingentes das práticas coletivas, questões essas que representam os grandes problemas epistemológicos da área, colocando em suspenso as tendências estruturalistas até então vigentes (Santos, 1997).

A teoria do risco social promoveu um extenso debate sobre a reflexividade da vida contemporânea e a presença constante da imponderabilidade e indeterminação como normas da modernidade. A busca pela inovação tecnológica, assentada no alcance de resultados incertos e instáveis, representaria a materialização do risco social e o desafio para a construção de uma sociedade democrática e sustentável (Beck, 1992). 
Para a inovação se fortalecer enquanto prática tecnológica, ela precisa apresentar sua positividade, seu potencial de articulação entre as máquinas e as instituições sociais. E nesse sentido, a indeterminação e insegurança garantem a originalidade e o sucesso dos procedimentos inovativos. Não pode haver uma inovação totalmente segura e predeterminada, a incerteza e o imponderável são constitutivos da atividade tecnológica (Stiegler, 1998). É fundamental assinalar que essa indeterminação e imponderabilidade do processo inovativo devem ser encontrados exatamente na constituição mesma dos objetos técnicos e não em um processo abstrato de aprendizado social.

Dois autores se sobressaem nessa discussão sobre os rumos da atividade tecnológica e o enfoque nos objetos técnicos, Gilbert Simondon e Bruno Latour. O exame de seus argumentos propicia um melhor enquadramento da discussão sobre inovação e as incertezas da prática tecnológica.

\section{Simondon e a teoria da concretização}

O filósofo das técnicas Gilbert Simondon (1969), que elaborou uma profunda teoria sobre a questão da individuação, articulando psicologia social e teoria da informação, teve grande impacto a partir dos anos 60 com sua discussão sobre os objetos técnicos e a teoria da concretização.

Para ele, todo objeto técnico tende a adquirir uma compatibilidade interna que promove um funcionamento cumulativamente mais sinérgico e auto-ajustado. Na medida em que os objetos técnicos se constituem de forma mais compatibilizada e orgânica, ampliam-se os procedimentos exteriores a eles e conseqüentemente os rumos possíveis de seu devir. A esse processo de compatibilização interna e acoplamento sinérgico dos objetos técnicos Simondon chama de concretização.

A constituição de um objeto técnico mais concreto e sinérgico, possuindo um rendimento superior em termos 
técnicos, solicita a conformação de um novo sistema técnico, mais reticular e avançado, que provoca necessariamente uma desestabilização nas condições de seu entorno (exemplo: máquina a vapor).

Simondon aponta claramente os problemas advindos de uma superposição de exigências econômicas sobre o ritmo do avanço técnico, e que precisam ser levadas em consideração na prática tecnológica.

"Existe uma convergência de limitações econômicas (diminuição de matéria-prima, de trabalho, e do consumo de energia durante a utilização) e de exigências propriamente técnicas: o objeto [técnico] não deve ser autodestrutivo. Ele deve manter um funcionamento estável pelo maior espaço de tempo possível. Desses dois tipos de causas, econômicas e propriamente técnicas, é necessário que as segundas predominem na evolução técnica...; sobretudo nos domínios em que as condições técnicas prevalecem sobre as condições econômicas (aviação, material de guerra) ocorrem os progressos mais ativos... Em efeito, as causas econômicas não são puras; elas interferem com um conjunto difuso de motivações e preferências que os atenuam [progresso técnico] ou mesmo revertem (gosto pelo luxo, desejo de novidades aparentes para os utilizadores, propaganda comercial).” (Simondon, 1969: 26).

Muitas vezes as imposições econômicas e organizacionais poluem o desenvolvimento tecnológico, tornando-o desajustado e redundante. Simondon chega a afirmar que no mundo contemporâneo é necessário salvar a técnica, contida dentro de esquemas e projeções distantes de sua lógica (Kechkian, 1983).

Seguindo com esse raciocínio, até que ponto o investimento racionalizado em formulação de políticas e incen- 
tivos governamentais e financeiros à inovação tecnológica não corre o risco de burocratizar o trabalho dos inovadores, dificultando o estabelecimento de espaços de experimentação e indeterminação, os quais, como foi visto, são essenciais à plena realização da inovação? Simondon propõe a formulação de uma disciplina de mecanologia, que permita uma aproximação maior dos técnicos e suas máquinas para além de uma funcionalidade restrita, e que permita um encontro aberto e incerto entre as propriedades técnicas e as demandas coletivas.

Na medida em que se acoplam a outros objetos, formando grandes sistemas técnicos, as máquinas ainda dispõem daquilo que o autor denomina margem de indeterminação, uma fresta em seu funcionamento que as permite dialogar com outros componentes técnicos e alterar sua própria constituição de forma imprevisível e aleatória.

“... a existência de uma margem de indeterminação dentro das máquinas deve ser entendida como existência de um certo número de fases críticas em seu funcionamento; a máquina que pode receber uma informação é aquela que localiza temporalmente sua indeterminação em instantes sensíveis, ricos em possibilidades... As máquinas que podem receber informação são aquelas que localizam sua indeterminação...” (Simondon, 1969: 141, grifo nosso)

Não pode haver avanço tecnológico e inovação técnica sem essa margem de indeterminação, essa abertura das máquinas para relações desconhecidas e abertas. É através da margem de indeterminação que os objetos trocam informações com seu entorno e podem aprimorar sua inserção em conjuntos técnicos mais amplos. A crítica elaborada por Simondon contra o automatismo vai no sentido de que as máquinas automáticas são fechadas em si mesmas, auto-suficientes e carentes de relações com seu meio. São, portanto, 
objetos técnicos previsíveis, porém precários, uma vez que têm mais dificuldade de dialogar com os outros componentes dos sistemas técnicos.

Ancorado no pensamento de Simondon, Stiegler (1998) alerta para o problema colocado pela interferência do sistema econômico e administrativo sobre a dinâmica da inovação e a transformação dos sistemas técnicos. Para ele, o excesso de planejamento e controle sobre o avanço tecnológico implica inserir variáveis não técnicas sobre a transformação propriamente técnica. Com isso, não é mais possível correr riscos ou realizar experimentações livres, uma vez que todo um aparato institucional, financeiro e econômico é construído em torno da prática inovativa.

Ou seja, o futuro precisa ser organizado e controlado, e a técnica precisa se submeter a regras e fórmulas de financiamento da área econômica e administrativa. Isso significa que os agentes sociais da inovação necessitam se adaptar a 156 práticas de investimento em que os aspectos indeterminados e instáveis da pesquisa tecnológica precisam ser necessariamente subtraídos. Nos termos de Stiegler,

"Em um ritmo de inovação constante, fatores desconhecidos não são mais aceitáveis; o movimento deve ser controlado sob o risco de haver um colapso na coerência global, a partir de onde os sistemas operam de forma complementar..." (Stiegler, 1998: 42).

A concepção dominante de desenvolvimento tende a colonizar o sentido da inovação e alijá-la de um de seus componentes mais ricos e férteis, a incerteza e a experimentação constante. A alteração nos rumos da atividade tecnológica e a periódica desestabilização dos sistemas técnicos por via da inovação tendem a ser estipulados aprioristicamente por intermédio de políticas definidas, instituições normativas e normas de gestão. 
O problema consiste em que os policy makers e gestores industriais pretendem, ao organizarem a prática inovativa e estabelecerem metas, projeções e mecanismos de avaliação, coordenar o avanço tecnológico e retirar seu aspecto de indeterminação e imprevisibilidade, os quais não constituem efeitos ou epifenômenos da atividade tecnológica, mas para Simondon, são as condições necessárias de sua gênese e desenvolvimento (Simondon, 1989).

O estreitamento progressivo entre desenvolvimento e inovação, alavancado continuamente por governos e empresas, tende a provocar uma descaracterização desta na medida em que a racionalização e modernização da esfera produtiva impõem padrões e projeções de resultados que não permitem uma abertura às múltiplas demandas coletivas, à contingência dos acordos sociais e nem à margem de indeterminação dos objetos técnicos em seu devir.

Outro aspecto importante dessa discussão é que no processo de concretização dos objetos técnicos, sobressai para Simondon o fato de que a articulação dos componentes não ocorre devido ao interesse explícito dos construtores, mas devido a tendências sinergéticas não planejadas, que ocorrem independentemente da intencionalidade:

"Cada componente no objeto concreto não é mais aquele cuja essência implica em corresponder ao cumprimento de uma função pretendida pelo construtor, mas a uma parte de um sistema no qual uma diversidade de forças opera e produz efeitos independentemente da intenção dos fabricantes..." (Simondon, 1969: 58).

$\mathrm{O}$ autor defende que o desenvolvimento dos objetos e sistemas técnicos é condicionado pelos ajustes que os homens e as máquinas constroem em seus constantes diálogos técnicos, e inexistem modelos que possam antecipar a configuração desses diálogos. 
É somente através da experimentação técnica, e não das deduções científicas, que o prolongamento das potencialidades técnicas adquire seu maior grau, pois para Simondon, teoricamente, o objeto técnico nunca pode ser plenamente conhecido, seu devir está sempre em aberto.

A filosofia das técnicas delineada por Simondon e seus seguidores (Stiegler, 1998; Feenberg, 1999) defende que as práticas de inovação tecnológica estão mais diretamente relacionadas à compatibilização interna e externa dos artefatos técnicos, o que implica em uma complexificação crescente das articulações entre objetos e sistemas.

Dentro dessa ressonância de influências recíprocas, a busca de uma eficiência produtiva localizada em um determinado setor e conjuntura econômica prejudica a busca de um futuro técnico aberto a saltos evolutivos descontínuos, próprios da evolução técnica (Simondon, 1969).

A teoria da concretização traz um alerta importante 158 para o pensamento social, a necessidade de se alterar o padrão de avaliação da eficiência técnica. Um indivíduo técnico não pode ser admitido ou refutado por seu potencial comercial ou de disponibilidade, mas mediante a compactação e coerência de seus componentes e os elementos de seu entorno (Santos, 1998; Shiva, 2001).

\section{Os contextos de inovação}

Seguindo outra direção, calcada no construtivismo, a perspectiva de Bruno Latour representa uma grande contribuição no sentido de aliar a agenda social com a prática tecnológica concreta. A análise exógena e excludente entre fatores sociais e técnicos conduz a relações arbitrárias e determinísticas envolvendo disseminação de máquinas e aproveitamento de determinadas fontes de energia.

Uma de suas grandes contribuições consiste em que o enfoque nos processos tecnológicos continua sendo crucial para se compreender a perspectiva da inovação. Um deter- 
minado contexto tecnológico só adquire coerência e sentido mediante trocas de informação que envolvem os agentes sociais e a oferta de técnicas e insumos disponíveis.

Sem o contato com a experiência técnica, que se desenvolve por meio de um processo aberto e indeterminado implicando: - adesão de técnicos, empresas, governos e consumidores; disponibilidade de ferramentas, componentes e patentes; alteração de legislação ou incentivos - não é possível entender o contexto da prática inovativa (Latour, 1992).

$\mathrm{O}$ aproveitamento de uma determinada tecnologia e sua conseqüente inovação envolve a busca compartilhada de suas propriedades intrínsecas e as condições circunstanciais de seu aproveitamento. Segundo Latour, não se pode imputar somente ao quadro das condições sociais o sucesso ou fracasso de uma dada inovação, mas às propriedades técnicas que por sua vez se transformam mediante a mobilização e adesão de um caldo de agentes diferenciados, humanos e não-humanos, formadores de um contexto técnico e social instável.

Latour denuncia veementemente o determinismo social embutido fortemente nos estudos sobre tecnologia, que seria responsável pelo estabelecimento de uma séria abstração sociológica, que desconecta as contingências sociais da operacionalização técnica.

"Os analistas que, com base em grupos de interesses, explicam como se dissemina uma idéia, como uma teoria é aceita ou uma máquina é rejeitada não têm consciência de que os mesmos grupos, os mesmos interesses que eles vêem como causas em suas explicações são conseqüência da extração e da purificação artificiais de um punhado de vínculos que provêm dessas idéias, teorias, ou máquinas”. (Latour, 2000: 233, grifo original). 
Só é possível compreender o fracasso ou êxito de um projeto tecnológico mediante o exame tanto das condições institucionais e coletivas de uma determinada conjuntura, como de fatores que são erroneamente denominados técnicos, pois envolvem processos de recrutamento de disponibilizações sociais. A existência per se de novas institucionalidades não deve negligenciar o enfoque em práticas tecnológicas concretas, pois estas delimitam a possibilidade de que novos arranjos políticos e culturais sejam promovidos.

A externalidade entre o técnico e o social é artificial e indevida, e a implementação de dispositivos multifuncionais e de alta compatibilidade externa e interna faz-se fundamental para atender demandas complexas, como ocorreu no caso do projeto do metrô Aramis em Paris (Latour, 1992).

Em sua análise sobre a construção de Aramis nos anos 60 e sua crise duas décadas depois, Latour aponta que se 160 conforma em torno dele uma troca incessante de informações e conhecimento. Este é um exemplo de projeto que se propôs a reformular um novo contexto técnico e social na confluência entre espaço urbano, recursos tecnológicos, posicionamentos jurídicos e o imaginário dos consumidores, mas que não foi levado adiante, devido a previsões prematuras de sua inviabilidade. Previsões estas que segundo o autor não se basearam plenamente em questões de viabilidade técnica, mas de uma série de interpretações cambiantes envolvendo ocupação do espaço urbano e cultura de consumo individual.

Policy makers, técnicos em engenharia, urbanistas e consumidores passam a configurar um contexto social de argumentações em torno de um projeto específico, de forma que os elementos tradicionais do paradigma schumpeteriano, como os mecanismos de mercado e os investimentos em $\mathrm{P} \& \mathrm{D}$, se tornam abstrações que não dão conta de explicar as escolhas tecnológicas e as controvérsias políticas. 
A crise de Aramis se deu por conta de um descompasso de encaminhamentos que cruzam aspectos operatórios com dispositivos passionais dos agentes direta e indiretamente envolvidos em sua configuração. E nesse caso específico as condições operatórias e sinérgicas do projeto, apesar de sua qualidade, não foram suficientes para sustentar sua continuidade. O objeto e o contexto configuram uma mesma relação, não sendo possível separá-los.

Quando Aramis foi desacreditado em sua condição operatória, todo o seu contexto perdeu consistência, e os inovadores perderam também terreno de ação. Segundo Flichy (1995), assim como os navegadores, os inovadores precisam ao mesmo tempo controlar as velas do barco (operação técnica) e as correntes marítimas (condições sociais e econômicas). Sem isso, é inviável conduzir projetos de inovação consistentes e de longo alcance.

Questão semelhante aparece na análise de Callon (1987) sobre o carro elétrico (VEL) na França. Problemas envolvendo articulação de componentes internos e comportamento de consumidores são distintos, mas complementares, perfazendo uma rede de relações dinâmicas e associadas.

"Se os usuários de automóveis rejeitam o veículo elétrico e mantêm suas preferências por diferentes tipos do automóvel tradicional, isso se dá por uma série de motivos, um dos quais é o problema de que os catalizadores se envenenam. São essas associações heterogêneas que os sociólogos não levam em consideração e que são responsáveis pelo sucesso de uma rede de atores específica...” (Callon, 1987: 97)

Nesse caso, os aspectos técnicos são indissociáveis do rol de preferências culturais e políticas que os agentes manifestam. O sucesso de um determinado projeto tecnológico secreta em seu interior uma série de condições favoráveis 
ou viáveis que a análise sociológica tradicional é incapaz de detectar.

A teoria da concretização elaborada por Simondon e a discussão dos contextos técnicos trabalhados por Latour e os construtivistas têm grandes implicações para a discussão da inovação tecnológica. O resgate de suas elaborações para a reflexão sobre a inovação e o avanço tecnológico teria duas consequências principais: em primeiro lugar, a inovação não deve significar desenvolvimento, em suas fórmulas lineares e evolutivas, mas desestabilização de relações, que irão se reordenar a partir do estabelecimento de novas institucionalidades sociais. Contingência e indeterminação se encaixam mais perfeitamente na discussão sobre inovação, e não o desenvolvimento econômico e as projeções de crescimento construídas a partir de critérios de eficiência e racionalidade.

Por outro lado, o determinismo tecnológico não pode 162 ser substituído pelo determinismo sociológico. O fato de redes, empresas e governos disponibilizarem conhecimentos e produtos não implica automaticamente processos de inovação, uma vez que os produtos e técnicas disponibilizados condicionam sua própria incorporação futura.

\section{Conclusão}

A tecnociência contemporânea está em contínua ebulição, de modo que os conhecimentos acumulados anteriormente não são necessariamente pré-condição para a formulação de novos projetos tecnológicos. O ritmo do progresso tecnológico, por seu caráter difuso e anárquico, em muitos momentos se sobrepõe aos critérios de competitividade econômica. As empresas precisam atentar mais ao ritmo acelerado das inovações do que aos produtos comercializados, que possuem uma vida útil cada vez mais curta e efêmera (Santos, 2000).

As tendências atuais do desenvolvimento tecnológico apontam para o caráter difuso e imprevisível que os proces- 
sos e arranjos setoriais estão adquirindo. Não é mais possível projetar de forma calculada e precisa as articulações possíveis de desenvolvimento tecnológico em uma era de aceleração contínua e auto-referente (Martins, 2003).

A evolução de uma linhagem técnica ocorre mediante o aperfeiçoamento dinâmico dos objetos técnicos, que se dá não em sua concepção e funcionalidade, mas dentro de sua própria realização. O caráter empírico e experimental do fazer técnico exige uma aproximação constante dos homens com seus respectivos objetos, o que não pode ser substituído por uma concepção abstrata de capital social, distante da realização dos artefatos técnicos.

Está se tornando mais claro para os cientistas sociais atuais a necessidade de uma aproximação crescente entre os pesquisadores e a prática tecnológica concreta. Não é mais possível tratar a problemática tecnológica de forma exógena, condenando ou aceitando os artefatos ou processos técnicos sem uma visão contingencial e intrínseca às suas manifestações. A crítica de determinados filósofos da tecnologia aos autores da Escola de Frankfurt, por exemplo, refere-se exatamente a um diagnóstico geral e abstrato ao desenvolvimento técnico, sem levar em conta as especificidades e montagens concretas dos objetos e seu entorno (Feenberg, 1999).

Há necessidade de uma aproximação entre a inovação enquanto conhecimento, e o conhecimento enquanto vivência técnica e cultural. A experimentação técnica representa a condição para a construção da inovação, tanto em suas dimensões culturais como operatórias.

Nesse sentido, os diversos atores sociais são percebidos como atuantes diretos na definição dos rumos da inovação tecnológica. Faz-se necessário investir em ferramentas analíticas abertas o suficiente para que a inovação seja decodificada em suas diversas manifestações, culturais e tecnológicas. 
Não apenas os agentes econômicos e científicos são capazes de determinar a prática tecnológica, mas também os atores sociais. Mas esses atores são incapazes de se apropriar do processo inovativo sem uma articulação qualificada com a tecnicidade. A circulação de conhecimento no mundo contemporâneo ocorre mediante a apropriação diversa dos artefatos técnicos por parte dos agentes coletivos, o que por sua vez demanda uma aproximação da cultura com a técnica (Simondon, 1989).

A tendência em se sobrevalorizar a gestão do conhecimento leva a se focar preponderantemente a forma e não o conteúdo da dinâmica inovativa. Corre-se o risco de exagerar o papel da gestão empresarial e tecnológica em detrimento da análise da prática dos agentes tecnológicos e leigos em suas interações.

Este artigo procurou apontar que a filosofia das técnicas desenvolvida nas últimas décadas possui um grande poten164 cial de se articular com a produção sociológica e econômica sobre a prática inovativa e gerar uma nova teoria sobre a relação entre tecnologia e desenvolvimento social. Faz-se necessário montar uma linha de continuidade entre a discussão dos objetos técnicos, a prática compartilhada da inovação e a abordagem institucional da tecnologia, sem o qual a compreensão da técnica moderna se dará apenas parcialmente.

\section{Thales Novaes de Andrade}

é professor do Departamento de Ciências Sociais da UFSCar e editor executivo da revista Ambiente $\mathcal{E} 2$ Sociedade

\section{Referências bibliográficas}

ALBAGLI, Sarita \& MACIEL, Maria Lúcia. Informação e conhecimento na inovação e no desenvolvimento local. In: Ciências da Informação, v. 33, n. 3, p. 9-16, set./dez., 2004. 
BARBIERI, José Carlos (Org.) Organizações inovadoras - Estudos e casos brasileiros. São Paulo: FGV, 2003.

BECK, Ülrich. Risk society - towards a new modernity. Londres: Sage, 1992.

CALLON, Michel. Society in the making: The study of technology as a tool for sociological analysis. In: BIJKER, Wiebe et al. (Eds.). The social construction of technological systems. Mass., Cambridge: MIT Press, 1987.

CASSIOLATO, José Eduardo \& LASTRES, Helena. Sistemas de Inovação: políticas e Perspectivas. In: Parcerias estratégicas, n. 08, p. 237-255, 2000.

CASTELLS, Manuel. A sociedade em rede. (Trad. de Roneide Majer). São Paulo: Paz e Terra, 1999.

. A galáxia da Internet. Rio de Janeiro: Jorge Zahar, 2003.

CASTELLS, Manuel \& HALL, Peter. Technopoles of the world: the making of 21st century industrial complexes. Londres: Routledge, 1994.

FEENBERG, Andrew. Critical theory of technology. Oxford: Oxford University Press, 1991.

- Questioning technology. Londres: Routledge, 1999.

FLICHY, Patrice. L'innovation technique - recents développements en sciences sociales vers une nouvelle theorie de l'innovation. Paris: La Decouverte, 1995. FREEMAN, Christopher. The economics of hope. Londres: Pinter, 1992.

. Economics of industrial innovation. Cambridge: MIT, 1982.

GIBBONS, Michael et al. The new production of knowledge. Londres: Sage, 1994.

GILLE, Bertrand. Histoire des techniques. In: Encyclópedie de la Pléiade. Paris: Gallimard, 1978.

KECHKIAN, A. Sauver l'objet technique - entretien avec Gilbert Simondon. In: Esprit, n. 76, Paris, abril 1983.

LATOUR, Bruno Aramis ou l'amour des techniques. Paris: La Découverte, 1992.

Ciência em ação - como seguir cientistas e engenheiros sociedade afora. (Trad. de Ivone Benedetti). São Paulo: Unesp, 2000.

LEMOS, Cristina. Inovação na era do conhecimento. In: Parcerias estratégicas, n. 08, p.157-179, 2000.

MACIEL, Maria Lúcia. O milagre italiano: Caos, crise e criatividade. Brasília: Paralelo 15, 1996.

. Inovação e conhecimento. In: SOBRAL, Fernanda et al.

(Org.) A alavanca de Arquimedes - ciência e tecnologia na virada do século. Brasília: Paralelo 15, 1997.

. Hélices, sistemas, ambientes e modelos. Os desafios à

Sociologia da Inovação. In: Sociologias, ano 3, n. 06, p. 18-29, 2001.

. Ciência, tecnologia e inovação: a relação entre conheci- 
mento e Desenvolvimento. In: BIB - Revista Brasileira de Informação Bibliográfica em Ciências Sociais, n. 54, p. 67-80, 2º semestre 2002.

MARTINS, Hermínio (Org.). Dilemas da civilização tecnológica. Lisboa: ICS, 2003.

MITCHEL, William. The city of bits hypothesis. In: SCHÖN, Donald; SANYAL, Bish (Eds.). High technology and low-income communities. Cambridge: MIT Press, 1999.

MOWERY, David \& ROSENBERG, Nathan. Trajetórias da inovação: A mudança tecnológica nos Estados Unidos da América no século XX. Campinas: Unicamp, 2005. NICOLAS, Françoise. \& MYTELKA, Lynn. L'innovation: Le clef du development. Paris: Masson, 1994.

PINCH, Trevor \& BIJKER, Wiebe. The social construction of facts and artifacts: Or how the sociology of science and the sociology of technology might benefit each other. In: BIJKER, Wiebe et al. (Eds.). The social construction of technological systems. Mass., Cambridge: MIT Press, 1987.

PUTNAM, Robert et al. Comunidade e democracia: A experiência da Itália moderna. Rio de Janeiro: FGV, 1996.

SANTOS, Boaventura Sousa. Pela mão de Alice, São Paulo: Cortez, 1997. SANTOS, Laymert Garcia. Tecnologia, natureza e a "redescoberta" do Bra166 sil. In: R. ARAUJO,

- Tecnologia, perda do humano e crise do sujeito do direito". In: OLIVEIRA, Francisco de \& PAOLI, Maria Célia (Orgs). Os sentidos da democracia: Políticas do dissenso e hegemonia global. Petrópolis: Vozes, 2000.

. Tecnologia e seleção. Variações sobre o estudo do humano. In: MARTINS, Hermínio (Org.) Dilemas da civilização tecnológica, Lisboa: ICS, 2003.

SCHUMPETER, Joseph Alois. Teoria do desenvolvimento econômico. (Trad. de Maria Sílvia Possas). In: Os pensadores, São Paulo: Abril 1982.

SHIVA, Vandana. Biopirataria. São Paulo: Vozes, 2001.

SIMONDON, Gilbert. Du mode d'existence des objects techniques. Paris: AubierMontagne, 1969.

. L'individuation psychique et collective. Paris: Aubier, 1989.

STIEGLER, Bernard. Technics and time 1. Stanford: Stanford University Press, 1998.

TRIGUEIR0, Michelangelo Giotto. O clone de Prometeu. Brasília: UnB, 2002. 


\section{ASPECTOS SOCIAIS E TECNOLÓGICOS DAS ATIVIDADES DE INOVAÇÃO}

\section{THALES NOVAES DE ANDRADE}

$\mathrm{O}$ artigo pretende discutir os aspectos sociais e tecnológicos presentes no tema da inovação. Percebe-se que a tradição schumpeteriana de análise sobre inovação negligenciou fatores culturais e políticos nas trajetórias tecnológicas. Nas últimas décadas, diversas correntes têm se dedicado a cruzar variáveis econômicas e sociais nos estudos sobre produção e difusão de conhecimento e inovação. Os estudos sobre os sistemas e ambientes de inovação reformularam o enfoque das análises inovativas, defendendo que a gestão e a organização dos fluxos de conhecimento e redes propiciam melhor compreensão dos rumos da atividade econômica e tecnológica. Mas essas correntes estão retirando importância da problemática propriamente tecnológica sobre a inovação, o estudo dos objetos e conjuntos técnicos e suas propriedades. O objetivo deste artigo é explicitar a necessidade de articulação entre os aspectos técnicos e sociais no tema da inovação. 
Palavras-chave: Inovação; Ambientes de Inovação; Tecnologia; Objetos Técnicos.

\section{SOCIAL AND TECHNOLOGICAL ASPECTS OF INNOVATION ACTIVITIES}

The article aims to discuss social and technical aspects underlying the debate on innovation. It is noted that the Schumpeterian tradition of innovation analysis underestimated cultural and political factors within technological paths. Over the last decades, many tendencies have dedicated to cross economic and social aspects in studies on innovation and knowledge production and diffusion. Studies concerning innovation systems and environments have rebuilt the focus on innovation, posing that management and organization of networks and knowledge flows provide a better understanding of technological and economic activities. But such tendencies have overlooked the technological questions concerning innovation, specially the study of technical objects and sets. The main objective of this article is to outline the need for an articulation of both technical and social aspects on innovation.

Keywords: Innovation; Innovation Environments; Technology; Technical Objects. 